\title{
Test Method and Equivalent Circuit Modeling of a PEM Fuel Cell in a Passive State
}

\author{
Shannon C. Page, Adnan H. Anbuky, Susan P. Krumdieck, and Jack Brouwer
}

\begin{abstract}
A novel test protocol is proposed for fuel cells that are in a nonfunctioning or passive state. Standard fuel-cell test methods are reviewed, along with the equivalent circuit models (ECMs) used to represent functioning or active fuel cells. Standard active tests focus on single cells, while the passive test is shown to be applicable to testing multiple cells. The passive test measures electrical characteristics of the fuel cell in the absence of electrochemical reactions. A simple ECM is developed to describe the cell behavior under the passive test conditions. Circuit model parameters of many series-connected cells can be acquired using the results of a single stack test. Proton exchange membrane fuel cells (PEMFCs) from three manufacturers were tested, ranging in system power from 12-500 W. Test results for each PEMFC exhibited similar behavior that is well predicted by the ECM. A strong similarity between a passive fuel cell and a double layer capacitor is discussed.
\end{abstract}

Index Terms-Capacitors, circuit modeling, electrochemical devices, fuel cells, testing.

\section{INTRODUCTION}

$\mathbf{F}$ UEL CELLS have undergone significant development in the last 15 years, spurred in part by their unique energy conversion characteristics, including high efficiency and minimal environmental impact at the point of use. Fuel cell technology is in the state of precommercialization development, with increasing interest in manufacturing and application issues.

A proton exchange membrane fuel cell (PEMFC) employs a hydrated polymer membrane as the electrolyte, which conducts hydrogen ions $\left(\mathrm{H}^{+}\right)$, but not electric current. The electrodes consist of activated carbon, with a finely dispersed catalyst (typically platinum) at the electrode-electrolyte interface. Many different designs for individual cells and stacks have been developed, manufactured, and then integrated into power systems with generation capacity of $10 \mathrm{~W}-100 \mathrm{~kW}$. Testing methods to monitor material properties and cell condition are needed for reliability of fuel cells in target applications such as backup power.

This paper presents a new testing technique that is versatile, simple, can be implemented on an entire stack, and indicates properties of individual fuel cells through numerical analysis.

Manuscipt received November 15, 2005; revised April 17, 2006. This work was supported by the Foundation of Research Science and Technology, through the Technology in Industry Fellowship, under Contract IESL0101. Paper no. TEC-00390-2005.

S. C. Page and S. P. Krumdieck are with the Department of Mechanical Engineering, University of Canterbury, Christchurch 8140, New Zealand (e-mail: Shannon.Page@canterbury.ac.nz; Susan.Krumdieck@canterbury.ac.nz).

A. H. Anbuky is with the Auckland University of Technology, Auckland, 1142, New Zealand (e-mail: Adnan.Anbuky@aut.ac.nz).

J. Brouwer is with the National Fuel Cell Research Center, University of California at Irvine, Irvine, CA 92697-3550 USA (e-mail: Jack.Brouwer@ nfcrc.uci.edu).

Digital Object Identifier 10.1109/TEC.2007.895857
The passive test technique probes the electrical properties of the fuel cell in the absence of electrochemical reactions, a strategy that was not previously reported.

Section II of this paper reviews the existing testing methods, describing the particular fuel cell properties measured. The results of these test methods are often interpreted with the aid of equivalent circuit models (ECM). Section III reviews the range of ECMs employed. Section IV illustrates the physical similarity between a PEMFC and a double layer capacitor (DLC). The experimental systems, including three distinct fuel cell designs, which are used to evaluate the new test method are described in Section V. The passive test method, experimental results, and qualitative analysis are presented in Section VI. Section VII details the proposed ECM, and describes the technique employed for acquiring the circuit model parameters. Section VIII demonstrates how the testing method and circuit model analysis is used to find the properties of each cell in a stack using the results from a single test. Finally, the concluding remarks are presented in Section IX.

\section{Review of Common Fuel Cell Testing Techniques}

Fuel cell testing methods are derived from general electrochemistry techniques. Material properties can be tested ex situ, as in [1] where the ionic resistance of the polymer membrane is measured. A cyclic voltammetry test method was used in [2] to investigate various PEM catalysts in a half-cell configuration. A range of testing approaches have been used for full fuel cells, stack assemblies, and working PEMFC systems. The main testing techniques are reviewed below, including voltage versus current $(V-I)$ curve evaluation, electrochemical impedance spectroscopy (EIS), and current pulse/interrupt methods.

\section{A. $V-I$ Evaluation}

The most common method of testing a PEM fuel cell is to obtain a steady-state $V-I$ curve of an operating cell or stack. The $V-I$ curve is generally obtained by keeping the fuel cell operating conditions constant (such as the temperature, gas stoichiometry, humidity, etc.) and measuring the steady-state voltage versus a set of current values. The $V-I$ curve can be characterised by either mechanistic (as in [3], [4]) or empirical (as in [5], [6]) model equations, resulting in a mathematical description of fuel cell performance. Analysis of the $V-I$ curves and resulting model equations allows the magnitude of the three main loss mechanisms to be inferred, as they influence the $V-I$ curve at different current values. Losses caused by the chargetransfer processes at the electrode-electrolyte interface (often referred to as activation loss) result in a relatively steep decline 
of the $V-I$ curve at low currents. Membrane ionic resistance, together with electronic resistance of the electrodes and currentcollectors, results in a linear decrease of voltage with increasing current at nominal operating currents. At high currents, a rapid decay in the $V-I$ curve is observed, due to a reactant/product reaching the limiting rate at which it can be transported to/from the reaction sites. This loss is generally referred to as diffusion or mass-transport loss.

Different loss mechanisms dominate different current ranges; however, each of them still affects the performance at all operating points. The $V-I$ curve provides the net performance of an active stack under a certain set of steady-state operating conditions. In order to identify the losses more clearly, and to assess the impact of operating conditions, a family of $V-I$ curves are often obtained, with the fuel cell being held at different operating conditions for each curve. Thus, $V-I$ curve evaluation is conducted in a laboratory, where accurate control over test conditions can be maintained.

\section{B. EIS Technique}

EIS or ac impedance testing is commonly employed for determining fuel cell properties. The technique consists of imposing a low amplitude sinusoidal voltage (or current) on the fuel cell, while it is operating at a specific level of current production (a certain point on the $V-I$ curve). The impedance is calculated by measuring the phase and amplitude of the current (or voltage) response at that condition. A frequency sweep is used (typically $10 \mathrm{mHz}-100 \mathrm{kHz}$ ) in order to obtain a full impedance spectrum (i.e., map the entire range of dynamic response characteristics). Usually, a functioning fuel cell is tested, in which case the ac perturbation is superimposed onto a dc load that can be changed to map the performance over the entire operating regime of the fuel cell.

EIS is accepted to be superior to steady-state $V-I$ curve evaluation for separating out and identifying the different loss mechanisms of a fuel cell, due to the association of certain loss mechanisms with particular frequency ranges [7]. For instance, at very high frequencies, the impedance is due to ohmic losses, predominantly the membrane ionic resistance. At intermediate frequencies, charge transfer resistance coupled with the DLC, also contributes to the impedance. Finally, at low frequencies, diffusion/mass-transport losses add to the measured fuel cell impedance [8], [9].

Despite the different loss mechanisms contributing to the impedance at different frequency limits, it is not always clear what specific features of the impedance spectrum relate to which physical, chemical, or electrochemical processes and features of the fuel cell. Multiple tests can be conducted in order to relate fuel cell processes and properties more clearly to features of the impedance spectra. In these cases, the fuel cell can be held at a different current density (as in [10], [11]) or other operating variable can be changed for each impedance test. Whereas this approach may provide more insight into the physical, chemical, or electrochemical features of the fuel cell that contribute to the impedance spectra, insight is not guaranteed and the testing process may become arduous and difficult to interpret. In addition,
EIS is limited to a single cell, and requires substantial electronic equipment. Most of us would agree that this technique is limited to laboratory testing only.

\section{Current Interrupt/Pulse Methods}

Current interrupt or current pulse methods have been proposed as a simpler technique (compared with EIS) for obtaining fuel cell properties. These methods involve subjecting a functioning fuel cell to a step change in current, and measuring the resulting voltage transient. A variation of this method involves subjecting a functioning fuel cell to a short duration current pulse [12], [13]. The main properties that can be obtained using this method are the ohmic resistance, calculated from the instantaneous change in potential, and charge-transfer loss, obtained from the gradual change in potential to a steady-state value [14], [15]. Longer voltage transients have been attributed to diffusion losses when, for example, a molten carbonate fuel cell was subjected to a current interrupt test [16]. As with EIS, current pulse/interrupt testing is implemented on a single cell only. In addition, current interrupt/pulse methods are limited to finding only certain features of fuel cell operation related to ohmic and activation losses.

\section{Activation Loss Analysis}

PEMFC testing has been reported with the specific aim of isolating and clearly identifying the magnitude of certain loss mechanisms. A common strategy is to conduct multiple tests with the fuel cell at different operating conditions. Isolating the activation loss associated with hydrogen and oxygen half-cell reactions at the cathode or anode is particularly challenging. For other electrochemical devices, such as batteries, a reference electrode is inserted in the electrolyte to isolate the losses occurring at each electrode. However, this is not practical for a PEMFC.

Wagner et al. [10], [11] conducted EIS with a symmetrical gas arrangement at open circuit. Two spectra were obtained, one with $\mathrm{H}_{2}$ at both electrodes, and the other with $\mathrm{O}_{2}$ at both electrodes. The loss associated with the anode and cathode was inferred from the $\mathrm{H}_{2} / \mathrm{H}_{2}$ and $\mathrm{O}_{2} / \mathrm{O}_{2}$ impedance spectra, respectively. Andreaus et al. [9], [13] isolated losses at the anode by conducting EIS while operating the cell as a hydrogen pump, reducing $\mathrm{H}_{2}$ at one electrode and oxidising $\mathrm{H}^{+}$at the other, with current densities of up to $500 \mathrm{~mA} / \mathrm{cm}^{2}$. O'Hayre et al. [17] demonstrated a loss present at the cathode but not at the anode of their planar fuel cell, which comprised a common membrane electrode with cells externally connected in series. Lateral ionic condition of the membrane causes internal currents to flow when adjacent cells are connected in series. Thus, a voltage drop at the open circuit is observed in each cell, except for the cell at the positive end of the stack, since no $\mathrm{O}_{2}$ is being reduced.

\section{Fuel CELl ECM}

ECMs are used to model fuel cell behavior, and interpret test results in relation to cell properties. Various models have been proposed, which vary significantly in terms of complexity and 


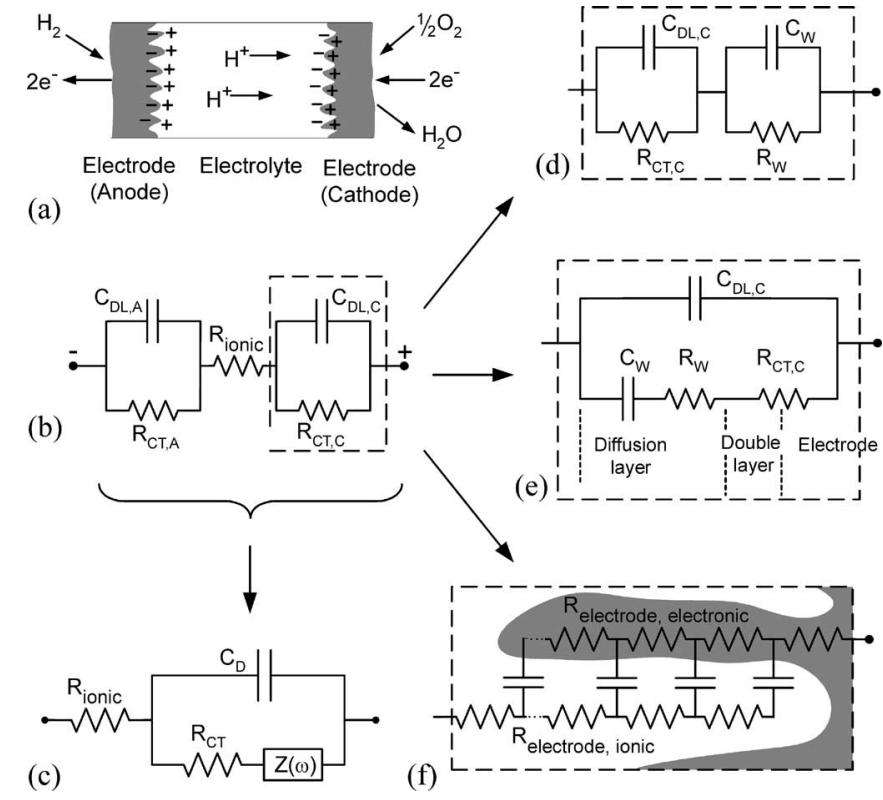

Fig. 1. (a) Simplified schematic of a functioning fuel cell (b) shown with the common ECM. (c) Simplified fuel cell model often used. Modifications on the cathode side to take into account diffusion impedance for (d) a fuel cell and (e) a general electrochemical cell. (f) Classic transmission line model of a porous electrode.

form. The purpose of certain models has been to simply replicate the terminal behavior of the fuel cell. For example, a circuit model that reproduces the $V-I$ curve and voltage transient behavior (induced by load changes) has been developed [18], [19], and a circuit that simulates the effects of inverter ripple current on a fuel cell has been proposed [20]. Other physical aspects of the fuel cell, such as changes in the gas partial pressures can also be included [21], [22]. These models are derived from net processes and thus, the ECM structure and component values are not directly related to physical properties. The following review focuses on ECMs that have been derived from physical and material considerations.

\section{A. PEMFC ECM}

The ECM most often used to represent a fuel cell is shown in Fig. 1(b), which is the basic model of any electrochemical cell [23]. $R_{\text {ionic }}$ represents the ionic resistance of the membrane, $R_{\mathrm{CT}, \mathrm{A}}$ and $R_{\mathrm{CT}, \mathrm{C}}$ represent the charge-transfer loss/resistance across the electrode-electrolyte interfaces at the anode and cathode, respectively.The capacitors $C_{\mathrm{DL}, \mathrm{A}}$ and $C_{\mathrm{DL}, \mathrm{C}}$ represent the DLC present at the anode and cathode electrode-electrolyte interfaces.

Current dependent resistances $R_{\mathrm{CT}, \mathrm{A}}$ and $R_{\mathrm{CT}, \mathrm{C}}$ have been introduced to account for the nonlinearity of the charge-transfer resistance [17]. $R_{w}$ and $C_{w}$ model the diffusion/mass-transport losses, and are shown in Fig. 1(d) for a fuel cell [11] and Fig. 1(e) for a general electrochemical cell [23]. The diffusion loss or impedance, commonly referred to as the Warburg impedance, has a long time constant leading to slow voltage transients induced by load changes [16].
A simplified model shown in Fig. 1(c) [15], [24], is commonly referred to as the Randel's equivalent. In this circuit, the charge double layers and the activation resistances have been combined into a single resistor and capacitor, respectively. A frequency-dependent component $Z(\omega)$ may be added to account for diffusion losses. This circuit has been widely used to model the essential dynamics of a fuel cell [25], [26], and for interpreting the results of current interrupt and EIS test methods [13]. Source component(s) (not shown in any of the models of Fig. 1) is sometimes included in series with the model terminals, or in series with one or both of the charge-transfer resistances.

The classic transmission line model of a single porous electrode, shown in Fig. 1(f), is used when specific properties of the catalytic layer are investigated [8], [27]. The model consists of an electronic resistor rail connected to an ionic resistor rail through capacitors, such that ionic and electronic charges must move through a range of resistance paths to charge the double layer completely. Clearly, this model does not take into account charge-transfer losses or any other active processes. Instead, the model represents the physical nature of the electrode-electrolyte interface, or catalytic layer.

\section{B. Techniques of Acquiring Circuit Parameters}

An EIS impedance spectrum is used to find the circuit parameters of an ECM in one of the two ways. In both the cases, the impedance as a function of frequency $Z(\omega)$ is derived for the circuit model in terms of circuit parameters. In the first method, the circuit parameter values are then found by fitting $Z(\omega)$ to the experimental impedance spectrum. This method can be used for finding the circuit parameters of a single cell, regardless of circuit model complexity; however, a good fit using a complex model, does not imply a unique or physically meaningful circuit model or parameter values. Alternatively, the circuit parameter values are derived from particular regions of the spectrum; for instance, at very high frequencies, the impedance of the circuit model reduces to $R_{\text {ionic }}$.

Voltage transients produced from current interrupt testing, and can be used to calculate the circuit parameters. For instance, the sudden voltage change gives the series resistance $R_{\text {ionic }}$, with longer voltage transients attributed to the charge-transfer resistance and DLC.

\section{Similarities With DLC}

The fuel cell models reviewed so far, along with the techniques employed for circuit parameter identification, are the same as those used for a general electrochemical cell, such as a battery or an electrolysis cell. A DLC is another electrochemical device that is physically similar to a fuel cell, and which exhibits a similar behavior particularly when the fuel cell is in a passive/nonfunctioning state. The testing techniques and circuit models employed for a DLC are briefly reviewed in this section.

\section{A. Physical Makeup of a DLC}

A DLC consists of two electrodes, separated by an electrolyte which contains free-moving ions. When charged, a double 
charge layer forms at each electrode-electrolyte interface. Due to a very small charge separation between the ions in the electrolyte and the charge on the electrodes, very high capacitance values are achieved. DLCs are sometimes referred to as super capacitors or ultra capacitors; however, these terms generally refer to devices in which the primary charge storage mechanism is different from the double charge layer, such as the absorption of electrolyte species into a solid crystalline electrode [28].

Activated carbon is most commonly used for the electrodes, which is the same electrode material used in most PEMFCs. DLCs usually contain an organic-based electrolyte, enabling higher voltages to be used before electrolyte breakdown occurs, which increases energy storage. Aqueous $\mathrm{H}_{2} \mathrm{SO}_{4}$ has also been used, and a number of DLCs employing Nafion (a polymer membrane common in PEMFCs) have been developed and tested [29]-[32]. The processes in a DLC differ from a PEMFC in that only non-Faradaic processes can occur, such as the movement and accumulation of ions and electrons, whereas in a fuel cell, Faradaic processes dominate, i.e., electrochemical reactions proceed due to a charge transfer between the electrolyte and the electrode.

\section{B. Testing and Modeling of DLCs}

Several testing methods have been employed to characterize the electrical behavior of a DLC, which differs significantly from an ideal capacitor. EIS has been used by [33]-[36], and entails conducting an impedance sweep on the capacitor. Repeated impedance spectra are sometimes obtained, with the DLC at various levels of charge for each test. The other technique used for testing a DLC involves dc charge and/or discharge processes. This method typically involves subjecting a single DLC to a constant current charge and/or discharge, and measuring the voltage transient response [21], [37]-[42]. An important part of the test result is the voltage transient after a charge period, where the DLC remains at open circuit.

A number of equivalent circuit models have been proposed that replicate the terminal behavior of a DLC. A multiple branched/ladder $R-C$ circuit, as shown in Fig. 2, is commonly employed. The model has been proposed with two [41], three [37], [40], or more [35] branches, depending on the time scale and accuracy required. A DLC possesses significant leakage current, e.g., a DLC sold commercially (by Maxwell) loses up to $1.5 \%$ of the stored energy per day through leakage current [43]. Many DLC models have a resistor $R_{L}$ across the model terminals to account for leakage current. The model shown in Fig. 2(c) was for highly dynamic simulations, and does not have an $R_{L}$ component. The authors stated that an $R_{L}$ could be added if predictions for longer times were required [33]. An inductor element is sometimes included when high frequencies are being modeled. However, as the inductor value tends to be small (of the order of nanohenries), it is often ignored.

The capacitance of a DLC has been shown to be a function of the applied voltage [38], [40], [44]. The ECM, therefore, includes one capacitor having the form $\mathrm{C}(V)=a+b V$ (where $a$ and $b$ are empirical constants) as shown in Fig. 2(a) and (b). With the exception of $R_{L}$, the circuit models tend to be empirical in

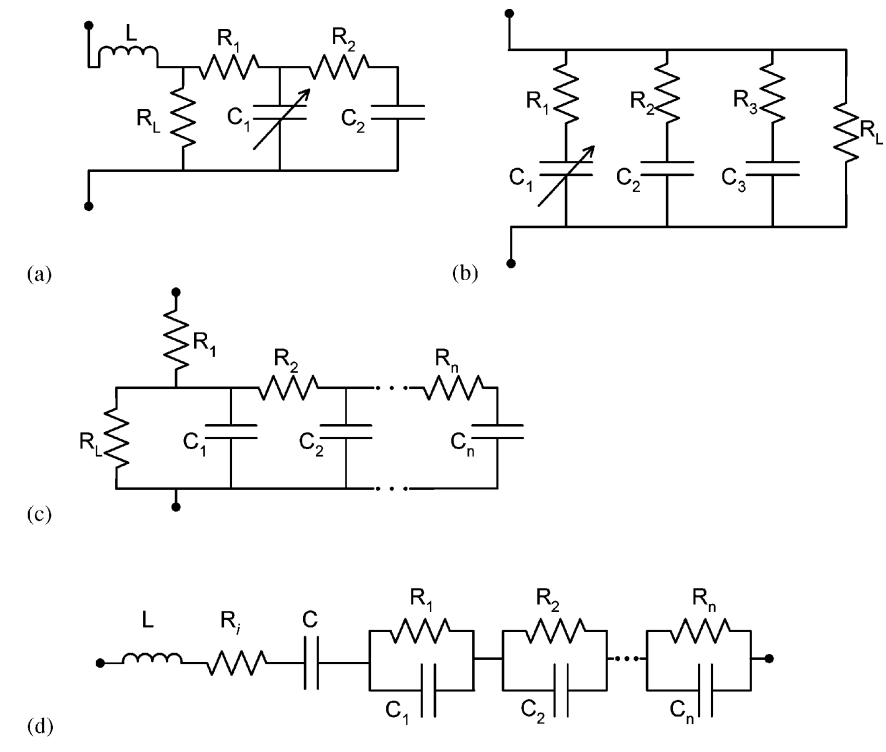

Fig. 2. Proposed ECMs of double charge layer capacitors.

nature, in that no physical meaning or process is associated with the other elements of the circuit model. Although more complex DLC models have been proposed, which are based on the transmission line model of an electrode-electrolyte interface, as shown in Fig. 1(f), they are not used for modeling the device.

\section{Acquiring Circuit Parameter Values}

Circuit parameters are typically calculated from the voltage transients produced during a charge/discharge test, requiring a number of assumptions. The $R-C$ branches are assumed to possess distinctly different time constants. From analyzing the voltage transient, particularly just after a charge period when the cell is at open circuit, it can be assumed that the transient at a certain time is primarily due to a particular $R-C$ branch. In addition, the initial voltage of the DLC is required to be zero; hence, the initial voltage of the capacitors in the model will also be zero. For this condition to be satisfied, [28] showed that a DLC must be short-circuited for a very significant length of time. Finally, whether EIS or dc charge/discharge testing is employed, the technique and corresponding analysis has only been reported in the literature for a single cell.

\section{EXPERIMENTAL TeSTING EQUIPMENT}

\section{A. Overview of Test System}

A system schematic of the test apparatus is shown in Fig. 3. A Hewlett \& Packard 34970A data acquisition/switch unit contains a HP34901A 20-channel multiplexer module for voltage sensing and a HP34907A multifunction module for regulated voltage output. A notebook computer running Matlab is used for controlling the HP meter and, hence, the test process, via an RS232 connection, with data sampled at $2 \mathrm{~Hz}$. Matlab is also used for data analysis and modeling. 


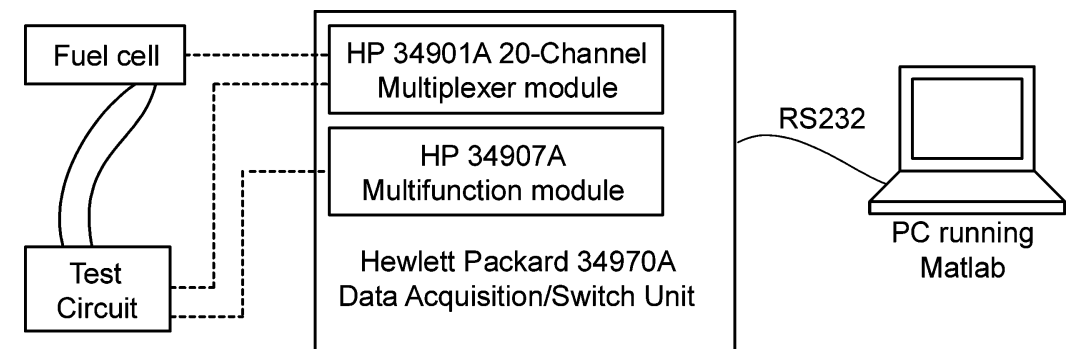

Fig. 3. Overview of experimental test system.

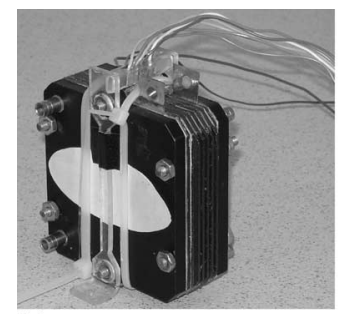

(a)

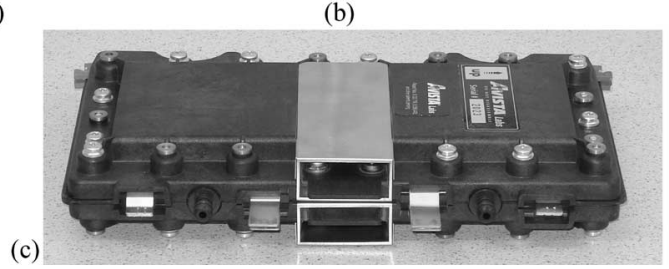

Fig. 4. Three fuel cells tested. (a) MerCorp. (b) Enable. (c) Single cartridge from an Avista SR-12.

\section{B. Fuel Cells Tested}

A low-power PEM stack manufactured by MerCorp is shown in Fig. 4(a), designed to operate up to $20 \mathrm{~W}$ ( $\sim 6.2 \mathrm{~A}$ and $3.2 \mathrm{~V})$. The stack consists of six series-connected cells, which have an active area of $31 \mathrm{~cm}^{2}$ and use a Nafion-based membrane electrolyte [45]. The construction of the stack is a typical bipolar design, with air and hydrogen in a counter flow arrangement. The stack is completely symmetrical, in that the electrode composition and flow field pattern are identical for the anode and cathode sides of each cell. Metal pins are clamped onto the side of each bipolar plate, allowing individual cells to be tested and monitored.

A 12-W (1 A and $12 \mathrm{~V}$ ) Enable fuel cell stack is shown in Fig. 4(b). The stack consists of 23 series-connected cells, each with an active area of $12 \mathrm{~cm}^{2}$. The stack is annular in design, with hydrogen introduced to the center of the stack (from both ends), and the air (through natural diffusion) entering the stack from the edges. Small clips attached to the metal separator plates of each cell allows individual cells to be tested and monitored.

An Avista SR-12 PEM fuel cell system, which produces up to $500 \mathrm{~W}$ ( $25 \mathrm{~V}$ and $20 \mathrm{~A}$ ) was also tested [see Fig. 4(c)]. The system contains 48 series-connected cells, which are grouped into 12 removable cartridges. Each cartridge contains four edge current collected PEM cells, each with an active area of $50 \mathrm{~cm}^{2}$. A Nafion-based membrane electrolyte is used, and the stack design is semipassive, with air being blown across a thick gas diffusion layer. Measurements were made on individual cells

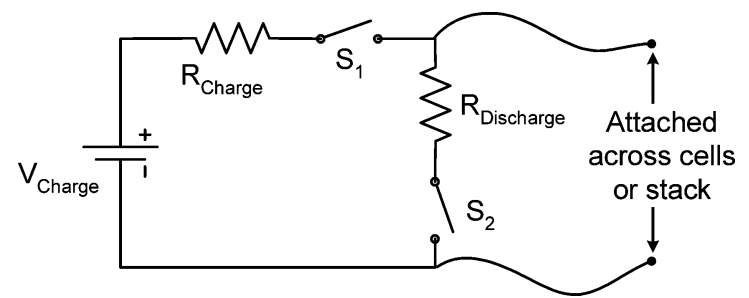

Fig. 5. Test circuit used for implementing the test protocol.

by removing a cartridge from the system, and connecting to the individual cell terminals.

\section{Test Method AND Results}

\section{A. Test Protocol Employed}

The test method is implemented while the fuel cell is in a passive, nonfunctioning state. No hydrogen is present in the stack, with air at both the anode and cathode; therefore, no electrochemical potential can form across any of the cells during the test. The electrical properties are then found using a sequence of dc electrical conditions, thereby charging and discharging the fuel cell in a capacitive sense. The simple test circuit shown in Fig. 5 is connected across a cell or a stack, and the test protocol is implemented by closing and opening the switches in the following sequence.

1) The initial voltages of the cell(s) and stack terminals are measured ( $S_{1}$ and $S_{2}$ initially open).

2) The fuel cell is charged, using a constant voltage source, $V_{\text {Charge }}$, in series with the resistor $R_{\text {charge }}\left(S_{1}\right.$ is closed).

3) The voltage source is disconnected, thus, placing the fuel cell in an open circuit condition ( $S_{1}$ is opened).

4) Charge held by the fuel cell is then dissipated through the resistor $R_{\text {dischage }}$ ( $S_{2}$ is closed).

5) The stack remains at open circuit for the remainder of the test ( $S_{1}$ and $S_{2}$ opened).

The test protocol has been implemented on an individual cell from each fuel cell stack. The resulting voltage transients are shown in Fig. 6. Model results for these cells are also shown in Fig. 6 as a dashed line, and are described later.

\section{B. Qualitative Discussion of the Test Voltage Transient}

The voltage transient produced by each cell is very similar, and consists of five distinct areas that have been labeled as: 1) initial steady state; 2) charge; 3) decay; 4) discharge; and 


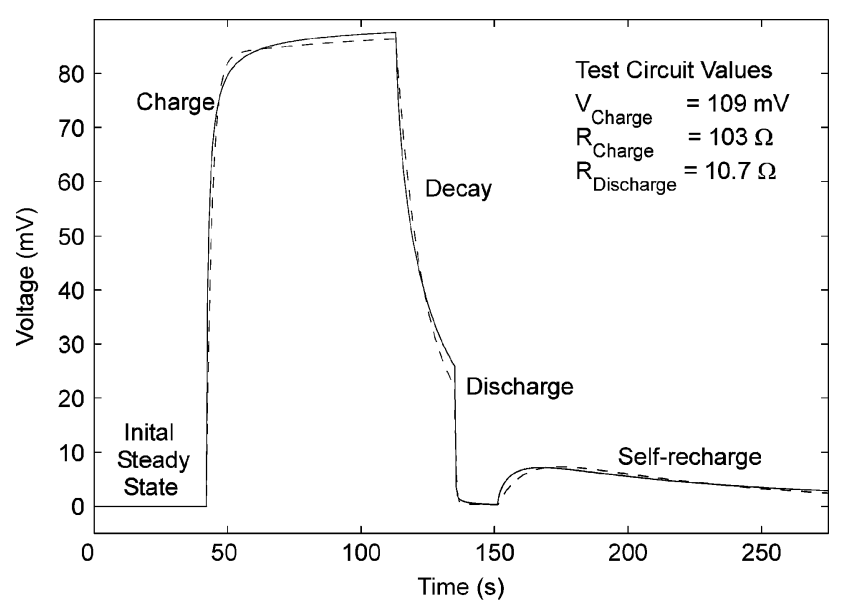

(a)

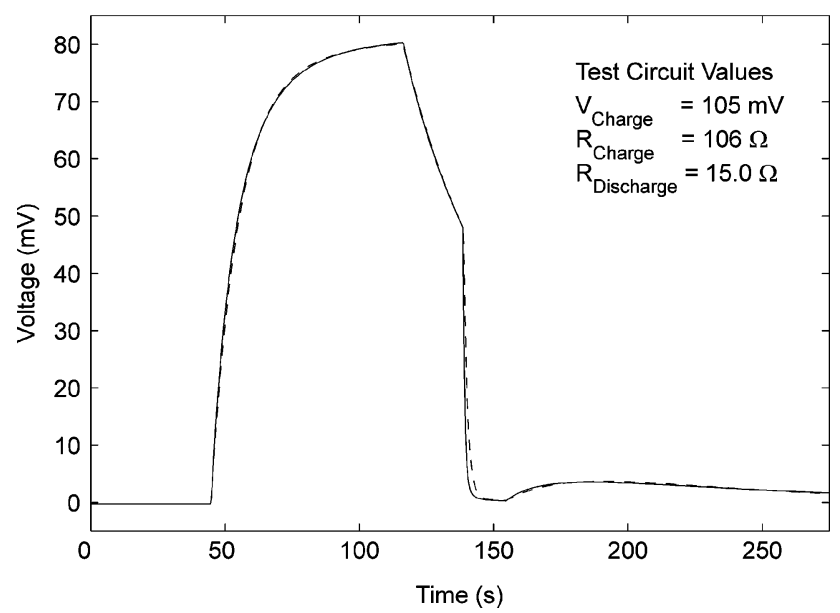

(b)

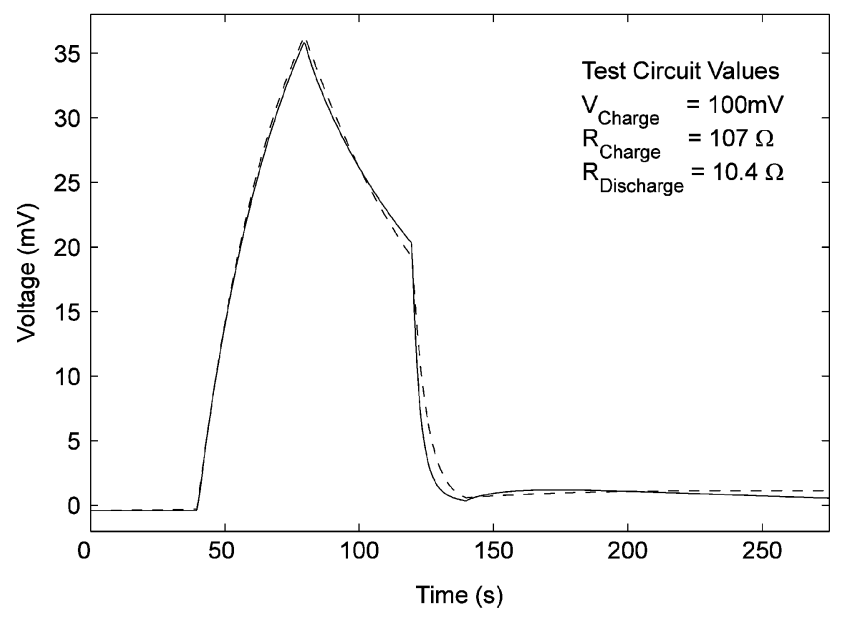

(c)

Fig. 6. Results for a single fuel cell. (a) MerCorp. (b) Enable. (c) Avista. Dashed line shows modeled results.

5) self-recharge. A qualitative discussion of each region is provided below.

1) Initial Steady State: At the beginning of a test, it was common for a cell to possess a small "resting" potential, which is recorded during the initial test period. Initially, the resting potential was attributed to fuel cell operation, days prior to the passive test. However, the resting potential was negative with respect to the polarity of the functioning cell. The results displayed in Fig. 6 only show a small resting potential; however, up to $40 \mathrm{mV}$ has been observed with certain Avista cells. The resting potential was measured on each of the three fuel cells tested, and also on many Avista cartridges using a separate Fluke meter. Research continues to find the cause of this small, curious, and common negative resting potential.

2) Charge: During the charge period, the cell is connected in series with a voltage source $V_{\text {charge }}$ and a resistor $R_{\text {charge }}$ (switch $S_{1}$ in the test circuit is closed). As the applied voltage is well below the level needed to decompose any water present in the membrane, the fuel cell acts primarily as a capacitor, resulting in an exponential rise in potential. In addition to the electric charge accumulating on the electrodes, hydrogen ions are believed to migrate towards the negative electrode, forming a double charge layer in a manner similar to a DLC. The rise in potential deviates significantly from a pure exponential function, as the fuel cell (like a DLC) does not behave like an ideal capacitor.

3) Decay: During the decay phase, the voltage source is disconnected $\left(S_{1}\right.$ opened) and the cell remains at open circuit. The potential clearly decays for each of the fuel cells tested. There are two processes thought to be responsible for the observed decay, leakage current, and continued ion movement in the membrane.

The leakage current of a DLC is well documented and because of the physical similarity between a fuel cell and a DLC, it is postulated that leakage current also occurs in the fuel cell. The exact mechanism by which leakage current occurs is still being investigated. Direct electronic conduction across the cell may occur, either through a defect in the membrane electrode assembly (MEA) or the surrounding cell assembly. Alternatively, as oxygen is present at both electrodes, and dissolved in the water present in the membrane, it is possible that the following half-cell reactions could occur:

$$
(+) \frac{1}{2} \mathrm{O}_{2}+2 \mathrm{H}^{+}+2 e^{-} \rightarrow \mathrm{H}_{2} \mathrm{O} \| \mathrm{H}_{2} \mathrm{O} \rightarrow \frac{1}{2} \mathrm{O}_{2}+2 \mathrm{H}^{+}+2 e^{-}(-) .
$$

A similar hydrogen-couple reaction could occur [9]; however, molecular hydrogen needs to be present at the positive electrode for it to occur.

The potential decay can also be attributed to the continued movement of hydrogen ions $\left(\mathrm{H}^{+}\right)$toward the negatively charged electrode. Again, this process can be compared with phenomena known to occur in a DLC. After charging a DLC, the potential decays rapidly to a new open circuit voltage value, then continues to decay at a slow rate. Clearly, the initial fast decay in cell voltage is not due to leakage current, but instead can be attributed to continued movement of ions, primarily at the porous electrode-electrolyte interface. Consider the transmission line model of a porous electrode-electrolyte interface [see Fig. 1(f)], and assume that the electronic resistance rail has negligible resistance. During a charge step, the capacitor nearest to the electrolyte will then contain more charge. After the charge step has ceased, hydrogen ions will continue to penetrate further into the porous electrode, thus, distributing the charge across all 


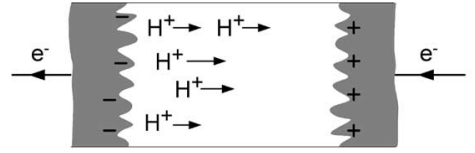

(a)

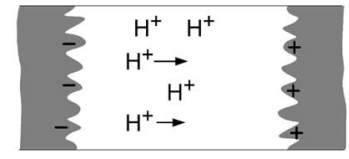

(b)
Fig. 7. Cell voltage (a) decreases during the discharge and (b) increases immediately after the discharge ceases resulting in self-recharge.

the capacitors in the model and reducing the potential across the cell. An alternative perspective, offered here for the first time, is that the membrane may possess a variable dielectric value depending on the position of the hydrogen ions within it. For instance, the closer the ions are to the negative electrode, assuming a fixed charge on the electrode, the higher the dielectric value. If a fixed charge remains on the electrodes, and the dielectric value of the membrane increases due to continued hydrogen ion movement, then the voltage across the cell (or capacitor) will decrease.

Additional experiments are required to determine the contribution of ion movement to the observed potential decay, and the various proposed leakage current mechanisms remain to be determined.

4) Discharge: During the discharge period, $S_{2}$ is closed, and the cell dissipates the accumulated charge through a resistor (with low resistance) so that nearly all of the charge is removed from the electrodes (the cell is effectively short-circuited during this period). As expected, and similar to any capacitor, the potential decays exponentially during discharge.

5) Self-Recharge: The observed self-recharge is an interesting phenomenon, since despite short circuiting the cell, the potential recovers to a certain point for a period of time before decaying back toward zero. Clearly, charges are still migrating inside the cell, giving rise to this transient voltage behavior. Potential recovery has been reported previously for DLCs, where the voltage recovers even after a short circuit period of a week or more [37].

Essentially, the processes that cause the voltage to decay after a charge step (primarily continued ion movement in the cell) are also thought to cause the self-recharge. During the discharge, almost all of the charge is dissipated off the electrodes, and the $\mathrm{H}^{+}$ ions begin to move back toward their original (homogeneous) position in the membrane. However, the distribution of hydrogen ions will still be nonuniform for some time after the charge on the electrodes has been reduced to near zero. Therefore, $\mathrm{H}^{+}$ ions will continue to move, and the effective dielectric value of the membrane will continue to decrease after the short has been removed. Assuming that a small amount of charge remains on the electrodes after the short is removed, together with the fact the dielectric constant is decreasing, the potential across the cell will increase. As the rise in potential reaches a maximum, it then begins to decay. Clearly, the cell is also conducting current by some leakage mechanism, as explained in Section VI-B3. A generalized representation of this ion diffusion in the electrolyte is shown in Fig. 7. The aggregate diffusion time constant arises from electrolyte physical chemistry, boundary layer thickness, and interface details, which are artifacts of materials, condition, and cell construction.
It is interesting to note the long time constant of the selfrecharge phenomenon. Long time constants are also observed during current interrupt tests of a functioning fuel cell, and are generally attributed to the rate of diffusion of chemical species.

\section{Summary of Single-Cell Test Results}

By measuring the transient voltage response of the cell to the test protocol, features related to the cells' physical makeup and operation are revealed, such as the movement of ions and the capacitance of the cell. In order to analyze the behavior quantitatively, an equivalent circuit model is developed, together with a method for acquiring circuit parameters.

\section{CIRCUIT Model ANALysis}

The standard model of a fuel cell cannot be employed for a fuel cell in a passive state for two reasons. First, because no hydrogen is present and the applied voltage is well below $1.2 \mathrm{~V}$, a substantial charge transfer across the electrolyte-electrode boundary does not occur. Therefore, the resistors $R_{\mathrm{CT}, \mathrm{A}}$ and

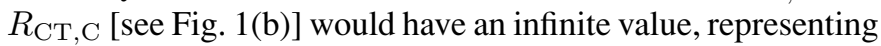
a break in the circuit. Second, since no electrochemical reactions are occurring, there is clearly no diffusion of reactants; thus, $R_{W}$ and $C_{W}$ [see Fig. 1(c)], which account for diffusion effects, will not be present. Hence, the standard model would be reduced to a series circuit consisting of $R_{\text {ionic }}$ and $C$, where $C=\left(1 / C_{\mathrm{DL}, \mathrm{A}}+1 / C_{\mathrm{DL}, \mathrm{C}}\right)^{-1}$. This circuit was proposed previously when considering a cell composed of an ideal reversible electrode and an ideal polarizable electrode, which by definition implies that no charge can be transferred across the electrodeelectrolyte boundary [24]. Clearly, a series $R-C$ circuit would not be capable of simulating the observed results of the passive test; thus, a passive PEM ECM is derived to describe the observed behavior.

\section{A. Derived ECM}

The basic physical elements of the fuel cell in a passive state are considered in developing the ECM. The electrodes are essentially two high surface-area conductors parallel to one another; thus, a capacitor $C_{a}$ is placed across the terminals of the circuit model as shown in Fig. 8. For charge to be stored on the electrodes (on $C_{a}$ ), current must pass through each electrode with a related contact resistance. Therefore, resistor $R_{c}$ is placed before the capacitor $C_{a}$. The presence of the membrane has a number of effects, one of which is the presence of leakage current. Hence, resistor $R_{a}$ is placed across capacitor $C_{a}$. The main effect that the membrane has on the cell is to increase its capacitance value. Therefore, capacitor $C_{b}$ is placed in parallel to $C_{a}$, with the addition of resistor $R_{b}$, which is related to the ionic resistance.

The values of the circuit parameters will clearly depend upon the physical makeup of the cell and, thus, may be used to indicate performance-related characteristics. For example, a larger $C_{a}$ would indicate a larger surface area, a property desirable in a cell. 


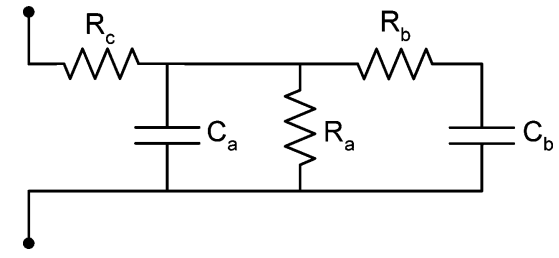

Fig. 8. Passive fuel cell equivalent circuit model.

TABLE I

Equivalent Cissrcuit Model Parameters for Single Cell Testing

\begin{tabular}{lcccc}
\hline \hline \multirow{2}{*}{ Fuel cell } & \multicolumn{4}{c}{ Circuit Parameters } \\
\cline { 2 - 5 } & $\mathrm{R}_{\mathrm{a}}(\Omega)$ & $\mathrm{R}_{\mathrm{b}}(\Omega)$ & $\mathrm{C}_{\mathrm{a}}(\mathrm{F})$ & $\mathrm{C}_{\mathrm{b}}(\mathrm{F})$ \\
\hline MerCorp Cell 2 & 552 & 1670 & 0.0243 & 0.0352 \\
Enable Cell & 309 & 1120 & 0.139 & 0.0320 \\
Avista Cell & 146 & 371 & 0.569 & 0.804 \\
\hline \hline
\end{tabular}

\section{B. Method to Acquire Circuit Parameters of a Single Cell}

The circuit parameters were obtained by conducting a least squares fit of simulated data to the experimental data. PLECS V1.0.9 (from Plexim $\mathrm{GmbH}$ ), which operates in the Matlab Simulink environment, was used for simulating the equivalent circuit model response to the test protocol. An iterative algorithm scripted in Matlab acquires the set of circuit parameters such that the least squares error between the simulated and experimental results is minimum. The initial voltage conditions of the capacitors in the circuit model are found by fitting the initial steady-state region, while holding the rest of the circuit values constant. This method of finding the circuit parameters is not confined to a particular model, and can be easily extended to find the circuit parameters of multiple connected cells (in a stack), as will be shown in Section VII. Using this method, the results of the single-cell tests are shown in Table I (in this case, the $R_{c}$ parameter was ignored, since it was found to be small in comparison to the other circuit values).

\section{Circuit Model Discussion}

The capacitive values $\left(C_{a}\right.$ and $\left.C_{b}\right)$ found for the Avista cell are significantly larger than for the MerCorp and Enable cells, which is to be expected considering the larger surface area of the Avista cell.

The simple four-element ECM reproduces the electrical response of the cell relatively accurately. As with DLCs, the capacitance may be a function of the applied voltage, and this aspect could be included if it was found to be important in an application.

When modeling a two terminal circuit device with four circuit elements, the model form is not unique. There are in fact three additional circuit models, each containing two capacitors and two resistors (but with different circuit values), that are indistinguishable at the model terminals. However, the circuit model form shown in Fig. 8 was derived from the physical attributes of a passive fuel cell. The resulting component values can be related to the physical elements of the cell. For example, the

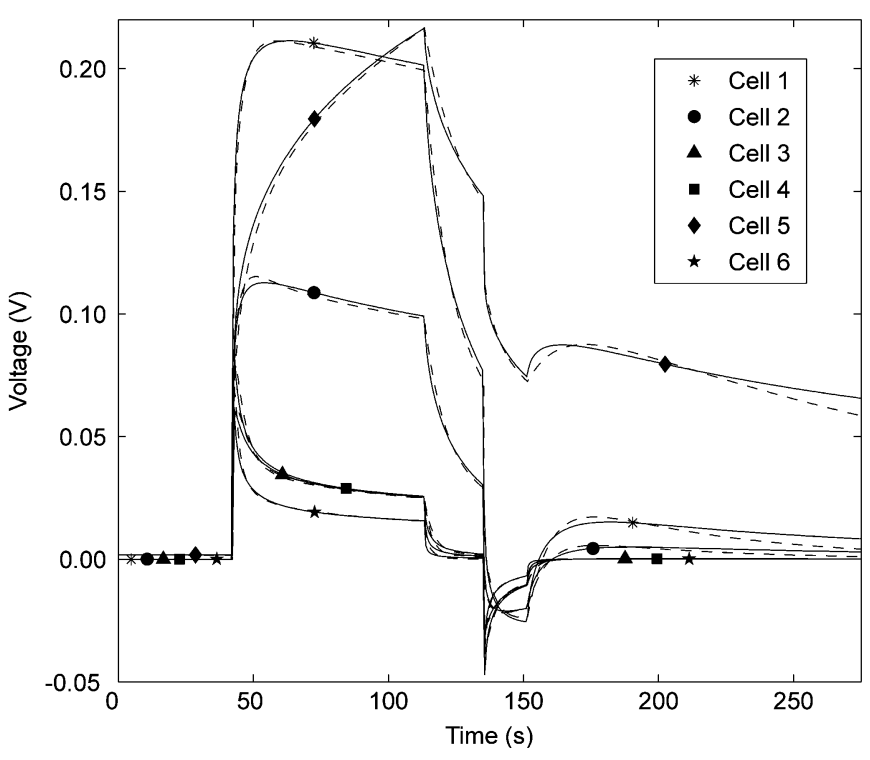

Fig. 9. MerCorp stack test results, dashed lines showing ECM results.

cell capacitance values relate to the dynamic characteristics of the cells, while the series resistance indicates the size of internal currents, possibly identifying a shorted (failed) cell. The functional relationship of the passive fuel cell ECM values to cell conditions is the subject of ongoing research.

\section{Stack Testing AND ANALYsis}

The passive PEM test method can be used to test an entire stack, simply by attaching the test circuit across the stack terminals. Any number of cells can be tested simultaneously by monitoring the individual cell voltages. Results for a stack test conducted on the MerCorp stack are shown in Fig. 9.

The interconnected cells have dynamic interrelationships, which effectively result in each cell being subjected to a different charge/discharge pattern as reflected in the voltage responses. Similar patterns were found with the Enable and Avista stack tests. This is easily explained by series-connected passive equivalent circuit, which has significantly different $R_{a}$ values for each cell.

The circuit parameters for the stack can be found using the PLEC model and the algorithm described above . An additional loop in the Matlab script file was added, so that the routine determines ECM parameters for each cell. The results are shown in Table II. The circuit values found for cell 2 during the singlecell test (Table I) and the stack test (Table II) are in reasonable agreement, demonstrating the validity of using a stack test to acquire the properties of multiple cells.

For this stack, a range of $R_{a}$ values was calculated from the test data. $R_{a}$ represents the membrane leakage current. Even though in the passive test, $R_{a}$ appears to vary significantly in an active cell, it is a minor factor. For instance, cell 6, which has smallest $R_{a}$ value, would have an absolute leakage current value of $7.2 \mathrm{~mA}$ that is significantly less than the stack (ionic) current of $6 \mathrm{~A}$. The very high sensitivity (large signal-to-noise ratio) of the passive test suggests that the technique could be 
TABLE II

Equivalent Circuit Model Parameters for Passive Stack Test

\begin{tabular}{lllll}
\hline \hline \multirow{2}{*}{ MerCorp Cell } & \multicolumn{4}{c}{ Circuit Parameters } \\
\cline { 2 - 5 } & $\mathrm{R}_{\mathrm{a}}(\Omega)$ & $\mathrm{R}_{\mathrm{b}}(\Omega)$ & $\mathrm{C}_{\mathrm{a}}(\mathrm{F})$ & $\mathrm{C}_{\mathrm{b}}(\mathrm{F})$ \\
\hline Cell 1 & 1000 & 1770 & 0.0150 & 0.0208 \\
Cell 2 & 477 & 1108 & 0.0257 & 0.0336 \\
Cell 3 & 116 & 1170 & 0.0322 & 0.0289 \\
Cell 4 & 117 & 2270 & 0.0235 & 0.0158 \\
Cell 5 & 2140 & 668 & 0.0278 & 0.0583 \\
Cell 6 & 73.7 & 436 & 0.0219 & 0.00645 \\
\hline \hline
\end{tabular}

very robust in practice, and especially useful when knowledge of $R_{a}$ variation is important.

The MerCorp cell was in the developmental stage, and the cells performed at different voltage levels. The active cell performance was found to correlate directly with the passive test results [46]. The passive test protocol, together with the property-based ECM and the numerical analysis method, to derive the cell parameters represent a novel approach to PEMFC monitoring [47].

\section{SUMMARY AND CONCLUSION}

A new testing method is introduced that examines the fuel cell in a passive state. The test method uses a charge/discharge test protocol, which is implemented using a simple test circuit. The testing method has been conducted on individual PEM cells from three different manufacturers, all of which show a similar voltage transient response to the test. The results reveal interesting voltage transients that are not due to electrochemical processes but to the physical nature of the cells themselves.

A passive PEMFC equivalent circuit model is proposed, and includes properties of the cell not previously considered, such as leakage current of the membrane, and a long time constant feature that is similar to a DLC due to the physical nature and response of the electrodes and membrane.

A novel method of obtaining the circuit model parameters is proposed and used to find individual cell circuit parameters from a single stack test.

The method was confirmed by reasonable agreement between ECM parameters obtained from an individual cell test and a stack test. The passive test protocol is simple, highly sensitive to some features of the cell, is implemented while the stack is in a passive state, and can measure properties of each cell with a single stack test.

\section{REFERENCES}

[1] S. Slade, S. A. Campbell, T. R. Ralph, and F. C. Walsh, "Ionic conductivity of an extruded Nafion 1100 EW series of membranes," J. Electrochem. Soc., vol. 149, pp. A1556-A1564, Dec. 2002.

[2] D. C. Papageorgopoulos, M. Keijzer, and F. A. de Bruijn, "The inclusion of Mo, Nb and Ta in Pt and PtRu carbon supported 3 electrocatalysts in the quest for improved CO tolerant PEMFC anodes," Electrochim. Acta, vol. 48, pp. 197-204, Nov. 2002.

[3] J. C. Amphlett, R. M. Baumert, R. F. Mann, B. A. Peppley, P. R. Roberge, and T. J. Harris, "Performance modeling of the Ballard-Mark-IV solid polymer electrolyte fuel-cell. 1. Mechanistic model development," $J$. Electrochem. Soc., vol. 142, pp. 1-8, Jan. 1995.
[4] J. C. Amphlett, R. M. Baumert, R. F. Mann, B. A. Peppley, P. R. Roberge, and T. J. Harris, "Performance modeling of the Ballard-Mark-IV solid polymer electrolyte fuel-cell. 2. Empirical-model development," J. Electrochem. Soc., vol. 142, pp. 9-15, Jan. 1995.

[5] J. Kim, S. Lee, and S. Srinivasan, "Modeling of proton exchange exchange with an empirical equation," J. Electrochem. Soc., vol. 142, pp. 26702674, Aug. 1995

[6] D. Chu, R. Jiang, and C. Walker, "Analysis of PEM fuel cell stacks using an empirical current-voltage equation," J. Appl. Electrochem., vol. 30 , pp. 365-370, Mar. 2000.

[7] T. E. Springer, T. A. Zawodzinski, M. S. Wilson, and S. Gottesfeld, "Characterization of polymer electrolyte fuel cells using AC impedance spectroscopy," J. Electrochem. Soc., vol. 143, pp. 587-599, Feb. 1996.

[8] G. C. Li and P. G. Pickup, "Ionic conductivity of PEMFC electrodesEffect of Nafion loading," J. Electrochem. Soc., vol. 150, pp. C745-C752, Nov. 2003.

[9] B. Andreaus, A. J. McEvoy, and G. G. Scherer, "Analysis of performance losses in polymer electrolyte fuel cells at high current densities by impedance spectroscopy," Electrochim. Acta, vol. 47, pp. 2223-2229, May 2002.

[10] N. Wagner, W. Schnurnberger, B. Muller, and M. Lang, "Electrochemical impedance spectra of solid-oxide fuel cells and polymer membrane fuel cells," Electrochim. Acta, vol. 43, pp. 3785-3793, Aug. 1998.

[11] N. Wagner, "Characterization of membrane electrode assemblies in polymer electrolyte fuel cells using ac impedance spectroscopy," J. Appl. Electrochem., vol. 32, pp. 859-863, Aug. 2002.

[12] F. N. Buchi, A. Marek, and G. G. Scherer, "In-situ membrane resistance measurements in polymer electrolyte fuel-cells by fast auxiliary current pulses," J. Electrochem. Soc., vol. 142, pp. 1895-1901, Jun. 1995.

[13] B. Andreaus and G. G. Scherer, "Proton-conducting polymer membranes in fuel cells-Humidification aspects," Solid State Ionics, vol. 168 , pp. 311-320, Mar. 2004.

[14] J. R. J. Larminie, "Current interrupt techniques for circuit modelling," in Proc. Inst. Electr. Eng. Colloq. Electrochem. Meas., London, U.K., 1994, pp. 12/1-12/6.

[15] J. Larminie and A. Dicks, Fuel Cell System Explained, 2nd ed. West Sussex, U.K.: Wiley, 2003, pp. 62-66.

[16] C. G. Lee, N. Nakano, T. Nishina, I. Uchida, and S. Kuroe, "Characterization of a $100 \mathrm{~cm}^{2}$ class molten carbonate fuel cell with current interruption," J. Electrochem. Soc., vol. 145, pp. 2747-2751, Aug. 1998.

[17] R. O'Hayre, T. Fabian, S. J. Lee, and F. B. Prinz, "Lateral ionic conduction in planar array fuel cells," J. Electrochem. Soc., vol. 150, pp. A430-A438, Apr. 2003.

[18] S. Yuvarajan and D. Yu, "Characteristics and modeling of PEM fuel cells," in Proc. Int. Symp. Circuits Syst., 2004, vol. 5, pp. V880-V883.

[19] D. Yu and S. Yuvarajan, "A novel circuit model for PEM fuel cells," in Proc. 19th Annu. IEEE Appl. Power Electron. Conf. Expo., 2004, vol. 1, pp. 362-366.

[20] W. Choi, P. N. Enjeti, and J. W. Howze, "Development of an equivalent circuit model of a fuel cell to evaluate the effects of inverter ripple current," in Proc. 19th Annu. IEEE Appl. Power Electron. Conf. Expo., 2004, vol. 1, pp. 355-361.

[21] C. S. Wang, M. H. Nehrir, and S. R. Shaw, "Dynamic models and model validation for PEM fuel cells using electrical circuits," IEEE Trans. Energy Convers., vol. 20, no. 2, pp. 442-451, Jun. 2005.

[22] R. S. Gemmen, "Analysis for the effect of inverter ripple current on fuel cell operating condition," J. Fluids Eng., vol. 125, pp. 576-585, May 2003.

[23] C. H. Hamann, A. Hemnett, and W. Vielstich, Electrochemistry. Weinheim, Germany: Wiley-VCH, 1998, p. 15, 240.

[24] A. J. Bard and L. R. Faulkner, Electrochemical Methods: Fundamentals and Applications, 2nd ed. New York: Wiley, 2001, pp. 14, 376.

[25] M. T. Iqbal, "Simulation of a small wind fuel cell hybrid energy system," Renewable Energy, vol. 28, pp. 511-522, Apr. 2003.

[26] M. T. Iqbal, "Modeling and control of a wind fuel cell hybrid energy system," Renewable Energy, vol. 28, pp. 223-237, Feb. 2003.

[27] N. Y. Jia, R. B. Martin, Z. G. Oi, M. C. Lefebyre, and P. G Pickup, "Modification of carbon supported catalysts to improve performance in gas diffusion electrodes," Electrochim. Acta, vol. 46, pp. 2863-2869, May 2001.

[28] R. A. Huggins, "Supercapacitors and electrochemical pulse sources," Solid State Ionics, vol. 134, pp. 179-195, Oct. 2000

[29] F. Lufrano, P. Staiti, and M. Minutoli, "Evaluation of nafion based double layer capacitors by electrochemical impedance spectroscopy," J. Power Sources, vol. 124, pp. 314-320, Oct. 2003. 
[30] F. Lufrano, P. Staiti, and M. Minutoli, "Influence of Nafion content in electrodes on performance of carbon supercapacitors," J. Electrochem. Soc, vol. 151, pp. A64-A68, Jan. 2004.

[31] P. Staiti, M. Minutoli, and F. Lufrano, "All solid electric double layer capacitors based on Nafion ionomer," Electrochim. Acta, vol. 47, pp. 27952800, Jul. 2005.

[32] P. Staiti and F. Lufrano, "Design, fabrication, and evaluation of a $1.5 \mathrm{~F}$ and $5 \mathrm{~V}$ prototype of solid-state electrochemical supercapacitor," J. Electrochem. Soc., vol. 152, pp. A617-A621, Jan. 2005.

[33] S. Buller, E. Karden, D. Kok, and R. W. De Doncker, "Modeling the dynamic behavior of supercapacitors using impedance spectroscopy," IEEE Trans. Ind. Appl., vol. 38, no. 6, pp. 1622-1626, Nov. 2002.

[34] C. Emmenegger, P. Mauron, and P. Sudan, et al., "Investigation of electrochemical double-layer (ECDL) capacitors electrodes based on carbon nanotubes and activated carbon materials," J. Power Sources, vol. 124, pp. 321-329, Oct. 2003.

[35] R. A. Dougal, L. Gao, and S. Liu, "Ultracapacitor model with automatic order selection and capacity scaling for dynamic system simulation," $J$. Power Sources, vol. 126, pp. 250-257, Feb. 2004.

[36] R. M. Nelms, D. R. Cahela, and B. J. Tatarchuk, "Modeling double-layer capacitor behavior using ladder circuits," IEEE Trans. Aero. Electron. Syst., vol. 39, no. 2, pp. 430-438, Apr. 2003.

[37] R. Bonert and L. Zubieta, "Measurement techniques for the evaluation of double-layer power capacitors," in Proc. 32nd IEEE Ind. Appl. Soc., Аnnu. Meet., Oct. 1997, vol. 2, pp. 1097-1100.

[38] L. Zubieta and R. Bonert, "Characterization of double-layer capacitors for power electronics applications," IEEE Trans. Ind. Appl., vol. 36, no. 1, pp. 199-205, Jan./Feb. 2000.

[39] L. Zubieta and R. Bonert, "Experimental $400 \mathrm{~kW}$ sec double-layer capacitor energy storage system," in Proc. 34th IEEE Ind. Appl. Soc., Annu. Meet., Phoenix, AZ, Oct.1999, vol. 4, pp. 2448-2453.

[40] L. Zubieta and R. Bonert, "Characterization of double-layer capacitors (DLCs) for power electronics applications," in Proc.33rd IEEE Ind. Appl. Soc., Аnnu. Meet., Oct. 1998, vol. 2, pp. 1149-1154.

[41] H. Gualous, D. Bouquain, A. Berthon, and J. M. Kauffmann, "Experimental study of supercapacitor serial resistance and capacitance variations with temperature," J. Power Sources, vol. 123, pp. 86-93, Sep. 2003.

[42] F. Belhachemi, S. Rael, and B. Davat, "A physical based model of power electric double-layer supercapacitors," in Proc. IEEE Ind. Appl. Conf., Oct. 2000, vol. 5, pp. 3069-3076.

[43] Maxwell Technologies, "Cell balancing in low duty cycle applications," Application Note. [Online]. Available: http://www.maxwell.com/ pdf/uc/app_notes/AN-002_Cell_balancing.pdf

[44] R. L. Spyker and R. M. Nelms, "Classical equivalent circuit parameters for a double-layer capacitor," IEEE Trans. Aero. Electron. Syst., vol. 36, no. 3, pp. 829-836, Jul. 2000.

[45] M. Hecht private communication, Sep. 2003.

[46] S. C. Page, S. P. Krumdieck, and A. Anbuky, "Testing procedure for passive fuel cell state of health," in Proc. Australia. Univ. Power Eng. Conf. Univ. Queensland, Australia, Sep. 2004.

[47] S. C. Page, A. Anbuky, and S. P Krumdieck, "Method of testing an electrochemical device," WO/2005/093447, PCT NZ/05/00053, Mar. 2005.

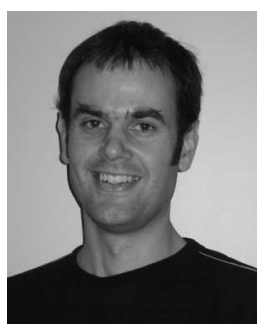

Shannon C. Page received the B.Sc. (Honors) degree in physics and Ph.D degree in mechanical engineering from the University of Canterbury, Christchurch, New Zealand, in 2000, and 2007 respectively.

$\mathrm{He}$ is currently with the University of Canterbury as a Research Associate, working in the area of energy constrained transportation systems. His research interests include fuel cell technology, specifically application and integration issues, energy system modeling, and sustainable energy systems.

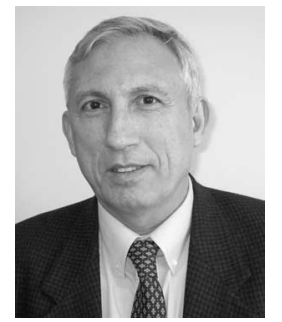

Adnan H. Anbuky received the B.Sc. degree in electrical engineering from the University of Baghdad, Baghdad, Iraq, in 1969, the M.Sc. degree from the University of Salford, Salford, U.K., in 1971, and the $\mathrm{Ph}$.D. degree from the University of Manchester Institute of Science and Technology, Manchester, U.K., in 1975 .

From 1975 to 1991, he was with the University of Technology, Baghdad, as an Academic Staff Member, becoming a Full Professor in 1987. From 1991 to 1995, he was with Yarmouk University, Irbid, Jordan, as the Head of the Computer Engineering Group and then as the Dean of the Faculty of Engineering. From 1996 to 2004, he was with Swichtec (currently Eaton Power Quality Limited), Christchurch, New Zealand, running a research unit on dc power systems management and other interrelated standby power technologies. He was the Director of Research with the Department of Electrical and Computer Engineering, Manukau Institute of Technology, Manukau, New Zealand, in 2005, and is currently the Head of the Department of Electrical and Electronic Engineering, Auckland University of Technology, Auckland, New Zealand.

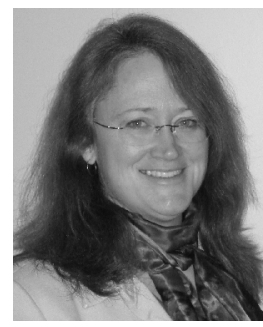

Susan P. Krumdieck received the B.S. and M.S. degrees in mechanical engineering from Arizona State University, Tempe, in 1986 and 1989, respectively, and the Ph.D. degree in mechanical engineering from the University of Colorado, Boulder, in 1999.

She started the company Boulder Material Systems with the aid of an NSF SBIR Award to commercialize the results of the Ph.D. research. She joined the University of Canterbury, Christchurch, New Zealand, in 2005, where she is currently a Senior Lecturer.

Dr. Krumdieck is a member of the Royal Society of New Zealand. During the Ph.D. study, she was a Link Foundation Energy Fellow, an ARCS Scholar, an SAE Doctoral Scholar, and the winner of the 1st and 4th place Air and Waste Management Association Scholarships.

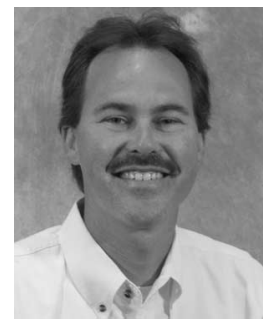

Jack Brouwer received the B.S. and M.S. degrees in mechanical engineering from the University of California at Irvine (UCI), Irvine, in 1987 and 1989, respectively, and the Ph.D. degree in mechanical engineering from Massachusetts Institute of Technology, Cambridge, in 1993.

He is an Adjunct Assistant Professor of Mechanical and Aerospace Engineering at UCI, where he is also an Associate Director of the National Fuel Cell Research Center (NFCRC). Prior to joining the NFCRC, he was a Research Faculty at the University of Utah, Salt Lake City, Utah, a Senior Engineer at Reaction Engineering International, Salt Lake City, and a Staff Scientist at Sandia National Laboratories, Livermore, CA. He is a regular instructor at UCI in the areas of fuel cells, thermodynamics, heat transfer, and combustion. He developed and introduced the first graduate level fuel cell course to UCI in 2001, and is a regular instructor in fuel cell short courses around the world. His current research interests include hydrogen refueling, fuel cell vehicles, hybrid fuel cell gas turbine systems, development and application of dynamic fuel cell and hybrid fuel cell systems simulations, and advancement of fuel processing technology. 